DOI 10.37882/2223-2974.2021.02.03

\title{
ЗЕМСКИЙ ВРАЧ 1864 ГОДА И «ЗЕМСКИЙ ДОКТОР» 2020 ГОДА: ЗАИМСТВОВАНИЕ ЛУЧШИХ ПРАКТИК ИЛИ НЕУДАЧНАЯ АНАЛОГИЯ (СРАВНИТЕЛЬНО-ПРАВОВОЙ АНАЛИЗ)
}

\section{ZEMSKY DOCTOR OF 1864 AND "ZEMSKY DOCTOR" OF 2020: BORROWING BEST PRACTICES OR AN UNSUCCESSFUL ANALOGY (COMPARATIVE LEGAL ANALYSIS)}

\section{K. Antonova}

Summary: In this article, the author examines the features of the implementation and legal regulation of the subprogram "Development of human resources in healthcare", which is part of the healthcare reform, conceived by the legislator back in 2010. This reform is now in the process; the terms of the programs have been extended until 2025. The purpose of this article is to analyze the current situation in the Russian Federation with regard to the implementation of the "Zemsky Doctor" programs, and the "Zemsky Paramedic" program is also partially affected. An analogy is drawn between the concepts of "Zemsky doctor" of 1864 and 2021, the author raises the question whether there is something in common between these phenomena, or whether today "Zemsky Doctor" is an unfortunate analogy that has nothing in common with this type of medicine of the XIX century. At the end of the article, the author's conclusions on the issue under consideration are presented that the implemented program is not an unsuccessful analogy, but has common key features that allow us to say that the name of the program "Zemsky Doctor" is justified.

Keywords: law, zemstvo, doctors, medicine, provision of medical services, medical workers, health care reform, zemstvo paramedic, benefits, compensation, development of human resources in health care, rural medicine.

\author{
Антонова Кристина Евгеньевна \\ аспирант, Тюменский государственный университет \\ kristy-tumen@mail.ru
}

Аннотация: В данной статье автор рассматривает особенности реализации и правового регулирования подпрограммы «Развитие кадровых ресурсов в здравоохранении», которая является частью реформы здравоохранения, задуманной законодателем еще в 2010 году. Данная реформа сейчас в процессе, сроки программ продлены до 2025 года. Целью написания данной статьи является анализ текущей ситуации в Российской Федерации, сложившейся в отношении реализации программ «Земский доктор», частично затрагивается и программа «Земский фельдшер». Проводится аналогия между понятиями «Земский врач» 1864 и 2021 годов, автором поднят вопрос, имеется ли что-то общее между этими явлениями, или же сегодня «Земский доктор»неудачная аналогия, общего с земской медициной XIX века, не имеющая. В конце статьи представлены выводы автора по рассматриваемому вопросу 0 том, что реализуемая программа не является неудачной аналогией, а имеет общие ключевые черты, которые позволяют говорить о том, что название программы «Земский доктор» оправдано.

Ключевые слова: право, земство, закон, врачи, медицина, оказание медицинских услуг, медицинские работники, реформа здравоохранения, земский фельдшер, льготы, компенсация, развитие кадровых ресурсов в здравоохранении, медицина сельской местности.
4 то представляет собой программа «Земский доктор» и «Земский фельдшер» нашего времени и связаны ли как-то эти понятия с земской медициной в том виде, в котором она зародилась и столь успешно функционировала с 1864 года?

Стоит отметить, что Законодатель уделяет большое внимание реформе здравоохранения и Направление (подпрограмма) «Развитие кадровых ресурсов в здравоохранении» государственной программы Российской Федерации «Развитие здравоохранения», куда входят «Земский доктор» и «Земский фельдшер», является одной из восьми, привлекших во внимание правительства, к которым относятся так же:

1. направление (подпрограмма) «Совершенствование оказания медицинской помощи, включая профилактику заболеваний и формирование здорового образа жизни»;

2. направление (подпрограмма) «Развитие и внедрение инновационных методов диагностики, профилактики и лечения, а также основ персонализированной медицины»;

3. направление (подпрограмма) «Развитие медицинской реабилитации и санаторно-курортного лечения, в том числе детей»;

4. направление (подпрограмма) «Развитие междуна- 
родных отношений в сфере охраны здоровья»;

5. направление (подпрограмма) «Экспертиза и контрольно-надзорные функции в сфере охраны здоровья»;

6. направление (подпрограмма) «Медико-санитарное обеспечение отдельных категорий граждан»;

7. направление (подпрограмма) «Информационные технологии и управление развитием отрасли».

Целью подпрограммы «Развитие кадровых ресурсов в здравоохранении» является ликвидация кадрового дефицита в медицинских организациях, оказывающих первичную медико-санитарную помощь, курируют которую Минздрав РФ, в частности.

Программа «Земский доктор» регламентирована Федеральным законом от 29 ноября 2010 г. № 326-Ф3 «Об обязательном медицинском страховании в Российской Федерации». По существу, суть программы была закреплена п. 12.1 статьи 50 «Программы и мероприятия по модернизации здравоохранения» вышеуказанного закона, согласно которому в 2017 году выплачиваются единовременные компенсационные выплаты медицинским работникам в возрасте до 50 лет с высшим образованием, прибывшим в 2016 и 2017 годах на работу в сельский поселок, рабочий поселок, поселок городского типа или переехавшие на работу в указанные населенные пункты, заключившем договор с уполномоченным органом исполнительной власти субъекта РФ, в размере одного миллиона рублей из расчета на одного медицинского работника. Финансовое обеспечение единовременных компенсационных выплат медицинским работникам в 2017 году осуществляется за счет иных межбюджетных трансфертов, предоставляемых в бюджет территориального фонда из бюджета Федерального фонда в соответствии с федеральным законом о бюджете на следующий финансовый год и на плановый период и средства из бюджетов субъектов РФ в соотношении соответственно 60 и 40 процентов. [17]

Данная программа направлена на внедрение стандартов медицинской помощи, повышение доступности амбулаторной медицинской помощи, в том числе предоставляемой врачами-специалистами, срок ее реализации был установлен на 2013-2017 годы. Ранее ее действие предполагалось до 2016 года, но этот срок был продлен до 2024 года [17] и на сегодняшний день программа продолжает функционировать.

Содержание программы определяется Постановлением Правительства РФ от 7 февраля 2011 г. № 60 и включает в себя деятельность органов исполнительной власти субъектов Российской Федерации по следующим направлениям [13]:

а) обеспечение укомплектованности медицинских организаций врачами-специалистами и специалистами со средним медицинским образовани- ем, оказывающими амбулаторную медицинскую помощь;

б) предоставление амбулаторной медицинской помощи, в том числе врачами-специалистами, в соответствии со стандартами ее оказания, включая обеспечение лекарственными препаратами и расходными материалами, необходимыми для проведения диагностических и лечебных мероприятий;

в) введение ориентированной на результаты деятельности системы оплаты труда врачей-специалистов и специалистов со средним медицинским образованием, оказывающих амбулаторную медицинскую помощь.

Этим же Постановлением определены и контролирующие органы - Федеральная служба по надзору в сфере здравоохранения и Федеральный Фонд обязательного медицинского страхования. [13] Также в этот перечень включены уполномоченные федеральные органы исполнительной власти и территориальные фонды. [17]

Таким образом верно будет сказать, что программы «Земский доктор» и «Земский фельдшер» - это мероприятия по поддержке медицинских кадров, переезжающих в сельские местности для оказания должного уровня медицинской помощи амбулаторно жителям территориальных образований, удаленных от крупных городов. Ранее имел место один барьер - программа распространяла свое действие на лиц, не достигших 50 лет. В 2020 году же были внесены изменения, [11] которые упразднили возрастной ценз и теперь условиями программы могут воспользоваться врачи и средний медицинский персонал по достижении 50 лет, однако возрастная дифференциация остается в части размера выплат: до 50 лет для врачей это 1 миллион рублей, после 50 лет - 500 тысяч рублей. Варьируется размер выплаты и в зависимости от региона, куда будет направлен медицинский работник (рис. 1.)

Распространяется программа на поселки городского типа, рабочие посёлки, села и маленькие города с населением до пятидесяти тысяч человек. В данной части не будет противоречий определению земской медицины, в содержании которой немаловажное значение имел территориальный критерий.

Имеются и ограничения в данной программе, к которым относятся [12]:

- целевое назначение выплаты,

- минимальные сроки действия трудового договора - 5 лет,

- наличие конкурса и требований определенного характера к участникам (российское гражданство, высшее образование, ординатура или интернатуpa). 


\section{РАЗМЕРЫ ВЫПЛАТЫ ПО ПРОГРАММАМ "ЗЕМСКИЙ ВРАЧ" И "ЗЕМСКИЙ ФЕЛЬДШЕР" В 2021 ГОДУ, ТЫС. РУБ.}

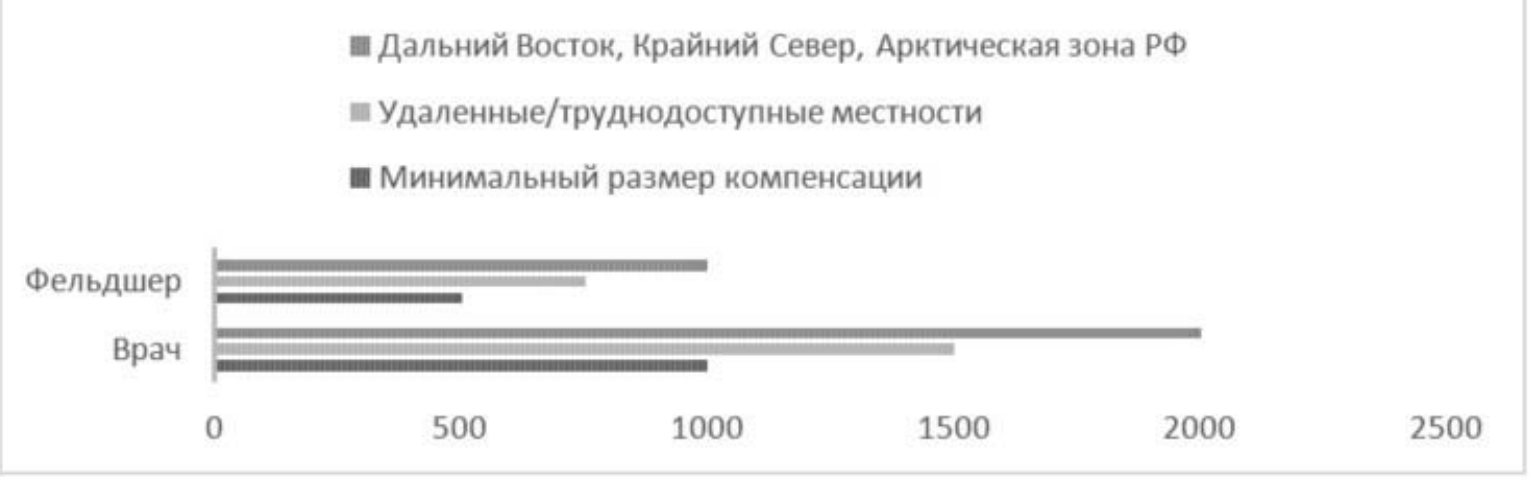

Рис. 1. Размеры выплаты по программам «Земский врач» и «Земский фельдшер» в 2021 году

Так, допускается потратить выплату только на улучшение жилищных условий: покупку дома, квартиры, земельного участка под строительство дома, жилого помещения, либо погашение ипотечного кредита или первоначального взноса по нему. Немаловажно отметить, что, если в переезжающей семье не один врач, выплата полагается каждому члену семьи при переезде соответственно. Однако, в случае нарушения критерия длительности трудового договора при преждевременном (до истечения пяти лет) его расторжении, необходимо будет вернуть сумму компенсации, пропорциональную оставшемуся периоду действия договора (например, врач отработал один год и решил уволиться, придется вернуть государству 800000 рублей, отработал два года из пяти - к возврату 600000 рублей и так далее).

Процедура для принятия участия в программах следующая [9]:

1. Врач узнает информацию о действующих вакансиях в территориальной единице, куда он хочет переехать, записывается на собеседование.

2. После успешного прохождения собеседования заключается трудовой договор.

3. Гражданин подает документы в местное управление или департамент здравоохранения вместе с заявлением о назначении единовременной компенсационной выплаты.

4. Заключается договор.

5. Выплата приходит на счет новоприбывшему врачу в течении 30 дней с момента заключения договора о компенсации.

Несмотря на кажущуюся простоту и легкость разрешения проблемы недостатка медицинских кадров в населенных пунктах с численностью населения менее пятидесяти тысяч человек, проблема эта не решается в полном объеме на текущий момент. Зерно этой неуда- чи можно увидеть в ментальности народа и специфике русского восприятия действительности. Так, еще в 2015 году Минздрав РФ давал следующий комментарий относительно 2012 года: «В результате в 2012 году контрольные проверки Федерального фонда ОМС выявили злоупотребления и массовые нарушения на муниципальном уровне, когда в заявки на получение единовременной компенсационной выплаты включались медицинские работники после непродолжительного увольнения и последующего возвращения на работу через две недели в то же медицинское учреждение. Также имели место выплаты медицинским работникам без соответствующего сертификата специалиста, принятым на неполную ставку по основной должности, на время отсутствия основного работника. Такие факты не способствовали решению кадрового вопроса и сокращению дефицита врачей в сельских населенных пунктах». [10]

Как видно, негативно на развитии программы сказалось и, на первый взгляд, положительное явление ассигнование со стороны государственного бюджета. Отсутствие ответственности муниципальных образований привело к наличию злоупотреблений со стороны последних, что привело к необходимости разделить финансирование программы - теперь часть денег должна быть изыскана за счет средств бюджета соответствующего субъекта федерации. Данный факт существенно затормозил процесс реализации. В том же комментарии Минздрав РФ указывает, что, например, «в нескольких регионах: Республиках Дагестан, Ингушетия, Тыва, Карачаево-Черкесской Республике в рамках программы «Земский доктор», действительно, не было принято ни одного медицинского работника. Однако необходимо отметить, что каждый субъект РФ принимает решение об участии в программе не только исходя из своих финансовых возможностей, но и в соответствии с реальными потребностями в молодых специалистах». [10] Нужно ли 
говорить о том, что такие результаты были скорее оправданы не отсутствием необходимости в медперсонале, а отсутствием либо нежеланием ассигнования программы местными властями.

Изучение опросов и форумов показало, что субъективная оценка медицинским персоналом программ «Земский доктор» и «Земский фельдшер» находится на низком уровне, подъемные, предлагаемые законодателем, не стимулируют представителей медицинского сообщества на принятие решения об участии в программах и переезд в сельские местности, а медики, прибывающие в указанные территориальные единицы, вынуждены уезжать, несмотря на необходимость возврата подъемных. Это связано с несколькими факторами (опционально, но отрицать их и не брать во внимание будет ошибочно):

1. Негативное отношение местного персонала к приезжающим врачам [6] - мотивировано, в частности, тем, что у местного персонала, уже работающего в больнице, возможность участия в программах не предусмотрена;

2. Низкая зарплата на месте назначения; [14]

3. Сложные условия жизни в селе в социально-бытовом секторе; [14]

4. Отсутствие перспектив для развития детей в сельских местностях;

5. Отсутствие финансирования в местных бюджетах [1] и, как следствие, отсутствие своевременной выплаты подъемных;

6. Отсутствие необходимого оснащения рабочего места и медицинских принадлежностей для лечения пациентов; [14]

7. Ответственность перед населением малого населенного пункта слишком высока, а запросы населения зачастую переходят границы - нет нормированного графика работы, благодарность сменяется негативным отношением.

Анализ источников о земской медицине изучаемого периода дает нам понимание, что такие факторы не были чужды и земским врачам в России рассматриваемого периода.

Так как программа «Развитие кадровых ресурсов в здравоохранении», куда входит направление «Земский доктор», направлена, как мы выяснили, на мотивацию через материальное стимулирование врачей, а отказы от участия основываются на субъективных суждениях, то рассматривать и анализировать мы будем сущность этого направления XXI века и доступные нам сегодня данные о реалиях жизни и элементов правового регулирования деятельности земских врачей XIX века по двум факторам:

1. Бытовые условия: обязанности, льготы, компенсации, мотивационный элемент;

2. Социальная составляющая: взаимоотношения врачей и пациентов, представителей медицины между собой.

Рассматриваться первый фактор будет на основании данных Государственного Архива г. Шадринска за 1871 1872 годы и текущих данных по Уральскому федеральному округу (куда территориально относится г. Шадринск сегодня).

Контракт земского врача в 1871-1872 годах включал в себя закрепление следующих условий [5]:

1. Устанавливался размер жалования от Земской Управы в год с утонением ежемесячной оплаты (100 рублей в месяц (1 200 рублей в год);

2. Обязанность иметь попечение о народном здравии на том участке, который будет назначен Управой, в случае необходимости (отсутствия врача) - на иных участках, с правом безвозмездного пользования лошадьми для проезда;

3. Обязанность надзора над деятельностью участковых повивальных бабок, фельдшеров и оспопрививателей;

4. Исполнение иных обязанностей, назначенных Уездной Управой, направленных на предупреждение болезней людей и животных, а также принятие мер по прекращению болезней, в случае их появления;

5. Во время пребывания в г. Шадринске оказывать медицинскую помощь его жителям;

6. Предусмотрено было расторжение контракта в одностороннем порядке с предварительным оповещением второй стороны за три месяца до предполагаемой даты расторжения.

Что касается настоящего времени, в 2019 году, согласно данным Росстата, средняя заработная плата врачей и работников медицинских организаций, имеющих высшее медицинское (фармацевтическое) или иное высшее образование, предоставляющих медицинские услуги (обеспечивающих предоставление медицинских услуг) государственной и муниципальной форм собственности по субъектам Российской Федерации за январь-март 2019 года по Уральскому федеральному округу составляет 46110 рублей [8]:

1. Курганская область - 24385 рублей;

2. Свердловская область - 34424 рубля;

3. Тюменская область:

3.1. Ханты-Мансийский авт. округ-Югра - 60726 рублей;

3.2. Ямало-Ненецкий авт. Округ - 85242 рубля;

3.3. Тюменская область без авт. округов - 40470 рублей;

4. Челябинская область - 30146 рублей.

По округам эта сумма выглядит следующим образом (в порядке убывания) [8]:

1. Дальневосточный федеральный округ - 56304 ру- 
бля;

2. Уральский федеральный округ - 46110 рублей;

3. Северо-Западный федеральный округ - 41030 рублей;

4. Сибирский федеральный округ - 31594 рубля;

5. Центральный федеральный округ - 30179 рублей;

6. Приволжский федеральный округ - 26563 рубля;

7. Южный федеральный округ - 25639 рублей;

8. Северо-Кавказский федеральный округ - 21779 рублей.

Говорить о том, что в среднестатистические расчеты включены города федерального значения, в которых уровень заработной платы значительно выше, чем по регионам (например, г. Москва [8] - 70680 рублей, Брянская область [8] - 23459 рублей), не стоит, но из представленных данных, несмотря на то, что информация консолидирована по 2019 году, можно сделать мотивированный вывод по уровню зарплат в территориальных единицах, куда направляются врачи по программе «Земский доктор» в 2021 году.

В целом, в Шадринском земстве зарплата земского врача была на высоком уровне. Для примера, по контракту для повивальной бабки в 1872 году, жалование установлено в размере 25 рублей в месяц (300 рублей в год), в 1874 году Земское Собрание IV созыва установила содержание врача - 1500 рублей в год. [3]

Относительно обязанностей для земского врача XIX века можно сказать следующее: исходя из условий контракта, рассмотренного выше, а также иных аналогичного периода, врач, прибывающий в земство, являлся врачом-универсалом, и его деятельность была направлена на оказание медицинской помощи населению по всем возможным областям медицины, сегодня же врачи сохраняют свою квалификацию и не обязаны выходить за ее рамки, допуск к участию в программе не дифференцируется по сфере деятельности врача, необходимость кадров определяется местными властями в кооперации с медицинскими учреждениями по месту.

Земскими учреждениями была разработана система поощрений и льгот для дополнительного стимулирования врачей на занятие должностей в земствах. Среди них были периодические прибавки к жалованию, «разъездные» и квартирные деньги, а также иное обеспечение, необходимое для оказания медицинской помощи населению. Так, согласно «Инструкции об обязанностях врачей, ветеринаров и пр.» 1869 года: «сельские врачи пользуются для разъездов по служебным делам обывательскими подводами с платежом прогонов из положенных им по штату разъездных денег, выдаваемых по третям года вперед... отчета в их израсходовании, не представляют. Для записывания прихода и расхода медикаментов, ... и других вещей выдаются Врачебным отделением каждому врачу и фельдшеру инвентарные те- тради» [4]. Стоит отметить, что сегодня законодатель на федеральном уровне не предусматривает компенсации переезда для заинтересованных в программе «Земский доктор» врачей, однако и необходимость возмещения командировочных расходов, как и самих командировок, в сферу интересов государства в рамках программы тоже не входит.

Таким образом, можно сделать вывод, что условия для земского врача 1860-х годов были значительно более привлекательны в части заработной платы в рассматриваемом ракурсе, несмотря на единовременную выплату врачам современным, но обязанностей на них возлагалось более, чем на врачей, прибывающих в сельские местности сегодня.

Если говорить о втором факторе, то немаловажное значение приобретает в этом контексте книга Вересаева В.В. «Записки врача», являющаяся своего рода жизнеописанием одного из этапов развития Викентия Викентьевича Вересаева, работавшего в должности земского врача в определенный период своей жизни, биографическая художественно-документальная повесть, которая помимо профессиональных описаний, содержит вопросы проблематики, этики и философии профессии, взаимоотношений между врачом и пациентами, между представителями врачебного сообщества.

В своих «Записках» Вересаев пишет: «Да, не нужно ничего принимать к сердцу, нужно стоять выше страданий, отчаяния, ненависти, смотреть на каждого больного как на невменяемого, от которого ничего не оскорбительно. Выработается такое отношение, - и я хладнокровно пойду ..., и меня не остановит у порога мысль о незаслуженной ненависти, которая меня там ждет. И часто-часто приходится повторять себе: «Нужно выработать безразличие!» Но это так трудно...» [7]. Этот момент, один из многих в книге, говорит о том, что ответственность, возлагаемая на врачей, приезжающих в небольшой населенный пункт сегодня, не отличается, по существу, от лежавшей на враче, приехавшем работать в земство в XIX веке, отношение людей к такому врачу, целителю, сначала благодарное, затем потребительское, а по итогу, чаще всего, негативное, так как врач, в силу своих профессиональных деформаций и необходимости, может поступать в рамках исполнения своих обязанностей не так, как хотелось бы страждущим, которые всегда жалостливы и субъективны к близким, которые могут стать пациентами такого врача.

Ненормированный график также имел место быть как в XIX, так и в XXI веке. «Первая обязанность каждого врача - быть человеколюбивым и в любом случае быть готовым оказать активную помощь людям любого ранга, одержимым болезнями. Поэтому любой врач обязан явиться по приглашению пациентов, чтобы оказать им помощь. Кто не сделает этого без особых юридических 
препятствий к этому, он за такую неисправность и неуважение к страдающему человечеству подлежит штрафу в размере не более ста рублей и аресту на срок от семи дней до трех месяцев» [7], - пишет Вересаев В. В. Несмотря на то, что человеколюбие было одним из основных постулатов оказания медицинской помощи, закрепленных на законодательном уровне Врачебным Уставом 1864 года, и анализ источников рассматриваемого периода времени говорит о том, что врачи этим человеколюбием обладали, благодарности представителям медицинского общества ни это, ни жертвенность и готовность прийти простому народу на помощь не приносило: «У нас общество не хочет затруднять себя лишними хлопотами; всю тяжесть оно сваливает со своих плеч на плечи единичных людей и жестоко карает их в случае, если они отказываются нести эту тяжесть» [7]. Несмотря на то, что книга «Записки врача» впервые была опубликована еще в 1901 году, она не потеряла актуальности и сегодня.

На основании изложенного можно сделать вывод о том, что все-таки общего у сегодняшних «Земских докторов» и земских врачей XIX века достаточно много, и одноименное название оправдано не только дефиницией «земства», которая означала бы глубинку нашей необъятной Родины, но и содержанием высокого понятия «земского врача» для людей, которые посвятили свою жизнь оказанию медицинской помощи населению не только в крупных городах, но и в населенных пунктах меньшей территории, численность которых составляет не более пятидесяти тысяч человек.

\section{ЛИТЕРАТУРА}

1. Интересно узнать о впечатлениях устроившихся и работающих по программе «Земский доктор». ВКонтакте. [Электронный pecypc] URL: https://vk.com/ topic-101869533_36869269?offset=20 Дата обращения: 20.01.2021 г.

2. «Юридическая социальная сеть». [Электронный ресурс] URL: https://www.9111.ru/questions/777777777724165/;https://www.9111.ru/questions/17077084/

3. ГАШ. Журналы Шадринского врачебного съезда 1874 года. Ф. 402. Оп. 1. Д. 2149. Л. 5.

4. ГАШ. Контракты за 1871-1872 гг. Ф. 492. ОП. 1. Д. 2146. Л. 2-3.

5. ГАШ. Контракты за 1871-1872 гг. Ф. 492. 0п. 1. Д. 2146. Л. 50-51.

6. Данные от исследования Врачебного форума «MedLinks - Вся медицина в Интернет». [Электронный ресурс] URL: https://medtalking.ru/viewtopic. php?id=1471\&p=2. Дата обращения: 20.01.2021,

7. Записки врача. В. В. Вересаев. Изд. 000 «Издательство АСТ», М., 2019. С. 267.

8. Итоги федерального статистического наблюдения в сфере оплаты труда отдельных категорий работников социальной сферы и науки за январь-март 2019 года. Федеральная служба государственной статистики - Росстат. [Электронный ресурc] URL: https://rosstat.gov.ru/storage/mediabank/itogmonitor01-19(1).html. Дата обращения: 23.01.2021 г.

9. Как медработнику получить до 2 миллионов рублей? Обзор программ «Земский доктор» и «Земский фельдшер». Соцправ.ру. [Электронный ресурс] URL: https://socprav.ru/programma-zemskiy-doktor. Дата обращения: 20.01 .2021 г.

10. Комментарий Минздрава России об эффективности программы «Земский доктор». Министерство Здравоохранения РФ. Новости. [Электронный ресурс] URL: https://minzdrav.gov.ru/news/2015/07/15/2449-kommentariy-minzdrava-rossii-ob-effektivnosti-programmy-zemskiy-doktor. Дата обращения: 20.01.2020

11. Постановление Правительства Российской Федерации от 18.10.2019 № 1347 «0 внесении изменений в государственную программу Российской Федерации «Развитие здравоохранения». [Электронный ресурс] URL: http://publication.pravo.gov.ru/Document/View/0001201910250016?index=0\&rangeSize=1. Дата обращения: 20.01.2021

12. Постановление Правительства РФ от 26 декабря 2017 г. № 1640 «0б утверждении государственной программы Российской Федерации "Развитие здравоохранения». [Электронный ресурc] URL: http://ivo.garant.ru/\#/document/71848440/paragraph/1:0. Дата обращения:20.01.2021

13. Постановление Правительства РФ от 7 февраля 2011 г. № 60 «0 порядке реализации мероприятий по повышению доступности амбулаторной медицинской помощи, проводимых в рамках региональных программ модернизации здравоохранения субъектов Российской Федерации». [Электронный ресурс] URL: http://ivo.garant.ru/\#/document/4192034/paragraph/1:0. Дата обращения: 20.01.2021

14. Программа «Земский доктор» - как оно в жизни. LiveJournal [Электронный ресурс] URL: https://doktor-killer.livejournal.com/4433054.html. Дата обращения: 20.01.2021

15. Программа Земский доктор 2021: условия и документы для получения 1 миллиона рублей. Субсидии.нет. [Электронный pecypc] URL: https://subsidii.net/ eshhjo-vyplaty/programma-zemskij-doktor-usloviya-i-dokumenty-dlya-polucheniya-1-milliona-rublej.html\#i-2. Дата обращения: 20.01.2021

16. Т.И. Волкова Материальное положение земского медицинского персонала в начале XX века. Ярославский педагогический вестник. 2010. № 4. Том. 1. C. $45-48$.

17. Федеральный закон от 29 ноября 2010 г. № 326-Ф3 «06 обязательном медицинском страховании в Российской Федерации» [Электронный ресурс] URL: http://ivo.garant.ru/\#/document/12180688/paragraph/9310/doclist/:0 дата обращения 20.01.2021

() Антонова Кристина Евгеньевна (kristy-tumen@mail.ru). 